American Journal of Infectious Diseases 5 (2): 109-111, 2009

ISSN 1553-6203

(C) 2009 Science Publications

\title{
Almond Consumption Decreases Fasting and Post Prandial Blood Glucose Level in Female Type 2 Diabetes Subject
}

\author{
${ }^{1}$ Parul Choudhary, ${ }^{1}$ Saroj Kothari and ${ }^{2}$ Vimal Sharma \\ ${ }^{1}$ Department of Foods and Nutrition, College of Home Science, India \\ ${ }^{2}$ Presenting author-Rajasthan College of Agriculture, \\ Maharana Pratap University of Agriculture and Technology, Udaipur 313001 India
}

\begin{abstract}
Problem statement: Population studies indicate that individuals who regularly consume nuts have reduced risk for cardiovascular diseases and diabetes. The beneficial role of almonds has been established with respect to serum lipid profile however, its beneficial effects on glycemia is still to be established. Aim of the study was to investigate the response of almond feeding on fasting and post prandial blood glucose levels in T2DM female subjects. Approach: Twenty female T2DM subjects (40-60 years), having mean height $151.59 \pm 6.02 \mathrm{~cm}$, body weight $59.3 \pm 10.57 \mathrm{~kg}$, BMI of $25.73 \pm 4.10 \mathrm{~kg} \mathrm{~m}^{-2}$ and fasting blood glucose levels between $130-180 \mathrm{mg} \mathrm{dL}^{-1}$, free from any other disease, non smoker, teetotaler participated in this study. The subjects continued their free life style and in addition were given to eat $10 \mathrm{~g}$ of raw almonds per day as part of their first meal. Twelve hours fasting and $2 \mathrm{~h}$ post prandial blood was analyzed for glucose in blood collected after finger prick by a sterile disposable stellate on glucose analyzer (one touch basic plus complete diabetes monitoring system life scan, Inc. USA). Results: The mean fasting blood glucose levels gradually decreased from $152.7 \pm 19.44$ (pre intervention) to $140.25 \pm 27.14,137.15 \pm 25.82,132.45 \pm 24.11$ and $126.05 \pm 26.48 \mathrm{mg} \mathrm{dL}^{-1}$ respectively after 1, 2, 3 and 4 week of almond feeding. Similarly post prandial glucose during $0,1,2$, 3 and 4 week were $216.5 \pm 51.08,194.50 \pm 48.31,194.55 \pm 63.78,177.75 \pm 43.33171 .0 \pm 42.43 \mathrm{mg} \mathrm{dL}^{-1}$ showing a decline. Conclusion: Almond feeding significantly $(\mathrm{p}<0.01)$ reduced both fasting and post prandial blood glucose levels in female T2DM subjects. The active principle and mechanism needs to be elucidated.
\end{abstract}

Key words: Almond, T2DM, fasting blood sugar, females

\section{INTRODUCTION}

Population studies indicate that individuals who regularly consume nuts have reduced risk for cardiovascular diseases and diabetes ${ }^{[1]}$. The beneficial role of almonds has been established with respect to serum lipid profile ${ }^{[2]}$ however, its beneficial effects on glycemia are still to be established. Some studies indicate that almond consumption decreases blood glucose $^{[3]}$ while others were unable to observe such effects $^{[4]}$. Although almost $50 \%$ of almond weight is fat, incremental intakes of $7 \mathrm{~g} \mathrm{day}^{-1}$ of this tree nut reduce Low-Density Lipoprotein (LDL) cholesterol concentration by $1 \%$, especially within the context of diets recommended by the National Cholesterol Education Program. Habitual almond consumption does not lead to weight gain $^{[4]}$ and their inclusion in lowcalorie diets appears to promote more weight loss than a comparable carbohydrate-based low-calorie diet.
Almonds in addition to lowering serum cholesterol levels may also reduce the glycemic impact of carbohydrate foods with which they are eaten ${ }^{[5]}$. Almonds are an excellent source of bioavailable $\alpha$ tocopherol and increasing their intake enhances the resistance of LDL against oxidation. In addition, the polyphenolic constituents of almonds have been characterized and found to possess antioxidant actions. The benefits of almonds for cardiovascular health, obesity and age related diseases appear promising and thus in the present investigation effects of almond addition to diet on fasting and post prandial blood glucose was investigated in T2DM female subjects.

\section{MATERIALS AND METHODS}

Almonds: American almonds (Prunus amygdalus) were purchased from the local market in single lot. Their proximate composition was determined using standard procedures and they contained protein $21.08 \%$, 
Am. J. Infect. Dis., 5 (2): 109-111, 2009

\begin{tabular}{|c|c|c|c|c|c|}
\hline $\begin{array}{l}\text { Sr. } \\
\text { No. }\end{array}$ & Name of the drug & Quantity (mg) & Active compound & $\begin{array}{l}\text { No. of } \\
\text { times }\end{array}$ & $\begin{array}{l}\mathrm{B}=\text { Before meal } \\
\mathrm{A}=\mathrm{After} \text { meal }\end{array}$ \\
\hline 1 & Gluco red & $5+500$ & Glibenclamide + Metformin $\mathrm{HCl}$ & 2 & B \\
\hline 2 & Diacon-M & $5+500$ & Glipizide and Metformin & 2 & A \\
\hline 3 & Diabend-M & $80+500$ & Gliclazide and Metformin $\mathrm{HCl}$ & 2 & B \\
\hline 4 & $\mathrm{X}$ met & 500 & Metformin $\mathrm{HCl}$ & 2 & B \\
\hline 5 & Glimcip 1 & 1 & Glimepiride & 2 & B \\
\hline 6 & Glynase-MF & $5+500$ & Glipizide and metformin $\mathrm{HCl}$ & 2 & B \\
\hline 7 & Metaglez-forte & $500+5$ & Metformin $\mathrm{HCl}$ and glipidzide in beta-cyclodextrin complex & 2 & B \\
\hline 8 & Pioglar & 15 & Pioglittazone & 2 & B \\
\hline 9 & Piopod-30 & 30 & Pioglitta zone & 2 & B \\
\hline 10 & Diabetrol SR & $5+500$ & Glibenclamide + metformin sustained release & 2 & B \\
\hline 11 & Metride-2 & 2 & Glimepiride & 1 & B \\
\hline 12 & Gemer-2 & 2 & Glimepiride & 2 & B \\
\hline 13 & G-REG-SR-1000 & 1000 & Metformin $\mathrm{HCl}$ sustained release & 1 & A \\
\hline 14 & Metformin $\mathrm{HCl}$ & 500 & Metformin $\mathrm{HCl}$ & 2 & A \\
\hline 15 & Glynace 50 & 50 & Gliclazide & 2 & B \\
\hline 16 & Trigluco red forte & $5+500+2$ & Glibenclamide metformin $\mathrm{HCl}$ and Rosiglitazone maleate & 2 & B \\
\hline 17 & Diabose 25 & 25 & Metformin $\mathrm{HCl}$ & 1 & B \\
\hline
\end{tabular}

fat $53.3 \%$, carbohydrate $(12.9 \%)$, moisture $(6.3 \%)$, fiber $(2.38 \%)$ and ash $(4.0 \%)$.

Subjects: Twenty locally residing female T2DM subjects (40-60 years) having fasting blood sugar 130$180 \mathrm{mg} \mathrm{dL}^{-1}$ volunteered (consent taken) in this study approved by Institutional ethical committee. Information regarding their history of diabetes, eating habits, medication (17 subjects took medications as shown in Table 1) was collected by interviewing them. Subjects resorting to smoking-drinking or suffering from any other disease were not included in the study. Their dietary intake of nutrient was ascertained prior to study by $24 \mathrm{~h}$ dietary recall for three consecutive days while their nutritional status was judged by height weight and BMI measurement.

Study protocol: These subjects continued their existing free life style in terms of eating habits, medication and activity pattern. Their blood glucose (both fasting and $2 \mathrm{~h}$ post prandial) was assessed at 0,7 th and 14 th day (these three gave the pre intervention status) after which they were provided with raw almonds @ $10 \mathrm{~g} \mathrm{day}^{-1}$ person $^{-1}$ and they were advised to consume the same with their first meal every morning. This intervention continued for four weeks and during which blood glucose (fasting and two hr post prandial) was estimated on weekly basis i.e.; on 21st, 28th, 35th and 42nd day of study. Blood collected after finger prick by a sterile disposable stillet was analyzed on Portable Glucose analyzer (one touch basic plus complete diabetes monitoring system Life Scan, Inc. USA)
Mean \pm SD values were calculated and Paired ' $t$ ' test was used to assess the effect of intervention.

\section{RESULTS}

These women of average age 51.60 \pm 6.07 (range 40-60 years) consumed on an average of $1274.94 \pm 307.65 \mathrm{Kcal}$ which was $91.6 \%$ of their energy requirement based on BMI. The average height $(\mathrm{cm})$, weight $(\mathrm{kg})$ and BMI $\left(\left(\mathrm{kg} \mathrm{m}^{-2}\right)\right.$ respectively were 151.59 $\pm 6.02, \quad 59.30 \pm 10.56, \quad 25.73 \pm 4.10$. Almond intervention had no effect on body weight and BMI of the subjects.

Data in Table 2 gives the fasting and post prandial blood glucose levels in the subjects. The observations prior to intervention were recorded thrice, these served as pretest control values. The mean fasting blood glucose levels at $0,1,2$ weeks pre intervention were $152.4 \pm 17.45,152.5 \pm 23.57,152.8 \pm 27.14$ while in the 4 weeks after almond intervention were $140.25 \pm 27.14, \quad 137.15 \pm 25.82, \quad 132.45 \pm 24.11$ and $126.05 \pm 26.48 \mathrm{mg} \mathrm{dL}^{-1}$ respectively. The effect of almond on lowering blood glucose was evident from the very first week and it successively decreased with the duration of intake (Table 2). Similarly, the mean post prandial blood glucose levels during preintervention period were $216.6 \pm 59.78,213.8 \pm 55.28$ and $218.7 \pm 53.31$. While after intervention they were $194.50 \pm 48.31, \quad 194.55 \pm 63.78, \quad 177.75 \pm 43.33$ and $171.0 \pm 42.43 \mathrm{mg} \mathrm{dL}^{-1}$. The effect of almond intervention on post prandial glucose was also evident after 1 week (Table 2). 
Am. J. Infect. Dis., 5 (2): 109-111, 2009

Table 2: Blood glucose levels before and after almond intervention

\begin{tabular}{|c|c|c|c|c|c|c|c|}
\hline & \multicolumn{7}{|c|}{ Blood glucose $\left(\mathrm{mg} \mathrm{dL}^{-1}\right)$} \\
\hline & \multicolumn{3}{|c|}{ Before almond intervention } & \multicolumn{4}{|c|}{ After almond intervention } \\
\hline & 0 day & 7th day & 14th day & 21st day & 28th day & 35 th day & 42nd day \\
\hline Fasting blood glucose & $152.4^{\mathrm{a}} \pm 17.45$ & $152.5^{\mathrm{a}} \pm 23.57$ & $152.8^{\mathrm{a}} \pm 27.14$ & $140.3^{\mathrm{b}} \pm 27.14$ & $137.15^{\mathrm{C}} \pm 25.82$ & $132.45^{\mathrm{d}} \pm 24.11$ & $126.05^{\mathrm{e}} \pm 26.48$ \\
\hline $2 \mathrm{~h}$ post pradial & $216.6^{\mathrm{a}} \pm 59.78$ & $213.8^{\mathrm{a}} \pm 55.28$ & $218.7^{\mathrm{a}} \pm 53.31$ & $194.5^{\mathrm{b}} \pm 48.31$ & $194.60^{\mathrm{b}} \pm 63.78$ & $177.80^{\mathrm{c}} \pm 43.33$ & $171.70^{c} \pm 42.43$ \\
\hline
\end{tabular}

\section{DISCUSSION}

The present study has demonstrated that inclusion of $10 \mathrm{~g}$ of almonds in diet of T2DM female subjects led to significant reduction in their fasting and post prandial blood glucose levels. T2DM and other age related disorders work in synergy to manifest health problems in elderly. The management of these thus becomes interrelated. Post prandial events have attracted much attention for the potentially important role they play in cardiovascular disease risk and diabetic complications ${ }^{[6]}$. A number of cohort studies have shown a negative association between nut consumption and risk of CVD diseases, cancers, glucose metabolism and insulin regulation ${ }^{[7]}$. Analysis of almonds and their seed coats demonstrated high level of antioxidants, phytochemicals and biologically active compounds in them ${ }^{[8]}$. Moreover, soluble fiber in almonds lowers cholesterol and controls blood sugar level in people with diabetes. The almond skin contains fiber, which is good for digestion. Regular almond consumption can thus be recommended as life style intervention to promote better health.

\section{CONCLUSION}

Almond feeding significantly $(\mathrm{p}<0.01)$ reduced both fasting and post prandial blood glucose levels in female T2DM subjects.

\section{REFERENCES}

1. Jenkins, D.J.A., C.W.C Kendall, A. Marchie, A.R. Josse, T.H. Nguyen, D.A. Faulkner, K.G. Lapsley and J. Blumberg, 2008. Almonds reduce biomarkers of lipid peroxidation in older hyper lipidemic subjects. J Nutr., 138: 908-913. http://jn.nutrition.org/cgi/content/abstract/138/5/908

2. Jenkins, D.J.A, C.W.C. Kendall, A.R Josse, S. Salvatore, F. Brighenti, L.S.A. Augustin, P.R. Ellis, E. Vidgen and A.V. Rao, 2006. Almonds decrease post prandial glycenemia, insulinemia and oxidative damage in healthy individuals. J. Nutr., 136: 2987-2992. http://jn.nutrition.org/cgi/content/abstract/136/12/2 987
3. Jennifer, C.L., M Marlene, M. Lefevre, F.L. Greenway and C.R. Jennifer, 2002. Effects of diets enriched in almonds on insulin action and serum lipids in adults with normal glucose tolerance or type 2 diabetes. Am. J. Clin. Nutr. 76: 1000-1006 http://www.ajcn.org/cgi/content/abstract/76/5/1000

4. Hollis, J. and R. Mattes, 2007. Effect of chronic consumption of almonds on body weigh in healthy humans. Br. J. Nutr., 98: 651-656. DOI: 10.1017/S0007114507734608

5. Josse., A.R., C.W. Kendall, L.S. Augustin, P.R. Ellis and D.J. Jenkins, 2007. Almonds and post prandial glycemia-a dose-response study. Metabolism, 56: 400-404.

http://linkinghub.elsevier.com/retrieve/pii/S002604 9506003891

6. Keefe, J.H., M. Neil, M.S. Gheewala and J.O. Keefe, 2008. Dietary strategies for improving post prandial glucose, lipids, inflammation and cardio vascular health. J. Am. College Cardiol., 51: 249-255. http://content.onlinejacc.org/cgi/content/abstract/51 /3/249?ct

7. Stampfer, H.F., J.E. Manson, E.B. Rimm, G.A. Colditz, B.A. Rosner, F.E. Speizer, C.H. Hennekens and W.C. Willett, 1998. Frequent nut consumption and risk of coronary heart disease in women: Prospective cohort study. Br. Med. J., 317: 1341-1345. http://www.bmj.com/cgi/content/abstract/317/7169 $/ 1341$

8. Garrido, I., M. Monagas, C. Gomez-Cordoves and B. Bartolome, 2008. Polyphenols and antioxidant properties of almond skins: Influence of industrial processing. J. Food Sci., 73: C106-115. DOI: 10.1111/j.1750-3841.2007.00637 